\title{
Hydrocarbon chain conformation in an intercalated surfactant monolayer and bilayer
}

\author{
N V VENKATARAMAN ${ }^{\mathrm{a}}$ and S VASUDEVAN ${ }^{\mathrm{a}, \mathrm{b}_{*}}$ \\ ${ }^{a}$ Department of Inorganic and Physical Chemistry, and \\ ${ }^{\mathrm{b}}$ Solid State and Structural Chemistry Unit, Indian Institute of Science, \\ Bangalore 560 012, India \\ e-mail: svipc@ipc.iisc.ernet.in
}

\begin{abstract}
Cetyl trimethyl ammonium (CTA) ions have been confined within galleries of layered $\mathrm{CdPS}_{3}$ at two different grafting densities. Low grafting densities are obtained on direct intercalation of CTA ions into $\mathrm{CdPS}_{3}$ to give $\mathrm{Cd}_{0.93} \mathrm{PS}_{3}(\mathrm{CTA})_{0.14}$. Intercalation occurs with a lattice expansion of $4.8 \AA$ with the interlamellar surfactant ion lying flat forming a monolayer. Intercalation at higher grafting densities was effected by a two-step ion-exchange process to give $\mathrm{Cd}_{0.83} \mathrm{PS}_{3}(\mathrm{CTA})_{0.34}$, with a lattice expansion of $26.5 \AA$. At higher grafting densities the interlamellar surfactant ions adopt a tilted bilayer structure. ${ }^{13} \mathrm{C}$ NMR and orientation-dependent IR vibrational spectroscopy on single crystals have been used to probe the conformation and orientation of the methylene 'tail' of the intercalated surfactant in the two phases. In the monolayer phase, the confined methylene chain adopts an essentially all-trans conformation with most of the trans chain aligned parallel to the gallery walls. On lowering the temperature, molecular plane aligns parallel, so that the methylene chain lies flat, rigid and aligned to the confining surface. In the bilayer phase, most bonds in the methylene chain are in trans conformation. It is possible to identify specific conformational sequences containing a gauche bond, in the interior and termini of the intercalated methylene. These high energy conformers disappear on cooling leaving all fifteen methylene units of the intercalated cetyl trimethyl ammonium ion in trans conformational registry at $40 \mathrm{~K}$.
\end{abstract}

Keywords. Intercalation; layered compound; surfactant assembly; conformation.

\section{Introduction}

Intercalation of surfactants into layered solids has been a subject of considerable interest with potential application as adsorbents of contaminants in water treatment ${ }^{1}$, as chemical sensors ${ }^{2}$ and as artificial membranes ${ }^{3}$. They are also of interest as crystalline models of lipid bilayers ${ }^{4}$. A variety of inorganic layered hosts, the smectite group of clays $^{5}$, layered double hydroxides ${ }^{6}$, graphitic oxide ${ }^{7}$ and transition metal thiophosphates $^{8-11}$, are known to intercalate surfactants. In these systems, cationic or anionic aliphatic surfactants are end-tethered to the internal surface of the galleries of the layered solid via coulombic interactions with the inorganic layer. Intercalation of surfactant molecules provides a route to convert the essentially hydrophilic internal

*For correspondence 
surface of an inorganic layered host into an organophilic one ${ }^{12}$, capable of "adsolubilizing" a variety of polar and non-polar molecules ${ }^{13}$, aliphatic alcohols ${ }^{14}$, aromatic hydrocarbons ${ }^{15}$ and even polymers ${ }^{16}$.

The properties of the intercalates are governed by the structure of the surfactant molecules in the galleries which can adopt a variety of structures - monolayer, bilayer, paraffin-type monolayer or bilayer-depending on the packing density and the length of the surfactant methylene 'tail'. When the grafting density is low the surfactant molecules usually lie flat with the molecular axis of their methylene chain parallel to the walls of the gallery. With increasing grafting density the methylene 'tail' of the surfactant adopts a paraffin-type monolayer or bilayer structure depending on the size, concentration and length of the chain. In addition, the relatively small energy difference between the trans and gauche conformers of the methylene chain allows for a great degree of conformational freedom for the 'tail', restricted only by the gallery dimensions.

In this study, we have looked at the conformation and orientation of the methylene 'tail' in a cationic surfactant intercalated within the galleries of layered cadmium thiophosphate for two different concentrations, i.e. grafting densities. The cationic surfactant studied was cetyl trimethyl ammonium bromide (CTAB). The host lattice, cadmium thiophosphate, is formed by the stacking of $\mathrm{CdPS}_{3}$ sheets, built from edgesharing $\mathrm{CdS}_{6}$ and $\mathrm{P}_{2} \mathrm{~S}_{6}$ polyhedra, with a van der Waals gap of $3.2 \AA$ (figure 1$)^{17}$. It undergoes a unique ion-exchange intercalation reaction in which guest cations are introduced into the galleries with an equivalent loss of cadmium ions from the lattice ${ }^{18}$. Intercalation occurs with a dilation of the lattice along the interlayer axis, the extent of which depends on the nature of the guest cation.

When crystals of $\mathrm{CdPS}_{3}$ are contacted with an aqueous solution of the cationic surfactant cetyl trimethyl ammonium bromide (CTAB), $\left[\mathrm{CH}_{3}\left(\mathrm{CH}_{2}\right)_{15}\left(\mathrm{CH}_{3}\right)_{3} \mathrm{NBr}\right]$, cetyl trimethyl ammonium (CTA) ions intercalate into the galleries to give $\mathrm{Cd}_{0 \cdot 93} \mathrm{PS}_{3}(\mathrm{CTA})_{0 \cdot 14}$.
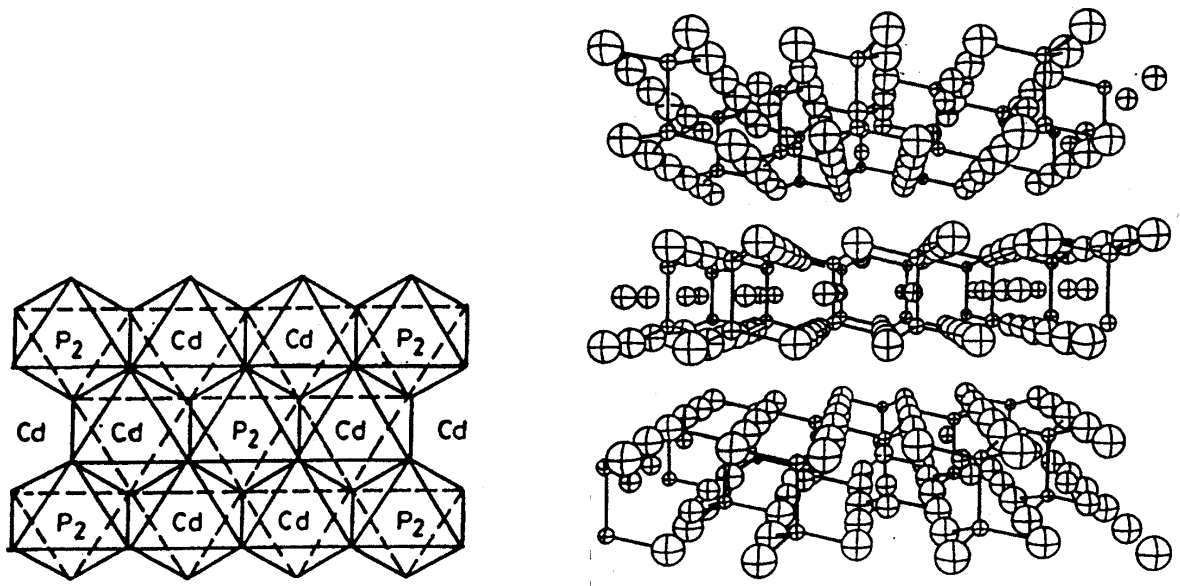

Figure 1. (a) A layer of $\mathrm{CdPS}_{3}$ showing the edge shared $\mathrm{CdS}_{6}$ and $\mathrm{P}_{2} \mathrm{~S}_{6}$ polyhedra. (b) Perspective view of $\mathrm{CdPS}_{3}$ structure as viewed along the $b$ axis showing the stacking of $\mathrm{CdPS}_{3}$ layers. 


$$
\mathrm{CdPS}_{3}+2 x \mathrm{CTA}^{+} \rightarrow \mathrm{Cd}_{1-x} \mathrm{PS}_{3}(\mathrm{CTA})_{2 x}+x \mathrm{Cd}^{2+}(\text { aq }), \quad(x=0-07) .
$$

Intercalation occurs with an expansion of the interlamellar spacing by $4-8 \AA$. This phase is henceforth referred to as the monolayer phase. Since the cross-sectional diameter of the methylene 'tail' is $\sim 4 \AA^{19}$, the gallery dimension still allows for some conformational freedom in the confining direction.

Higher grafting densities of the intercalated CTA ion may be obtained by a two-step intercalation process, in the first step hydrated potassium ions are ion-exchange intercalated $^{20}$,

$$
\mathrm{CdPS}_{3}+2 x \mathrm{~K}_{(\mathrm{aq})}^{+} \rightarrow \mathrm{Cd}_{1-x} \mathrm{PS}_{3} \mathrm{~K}_{2 x}\left(\mathrm{H}_{2} \mathrm{O}\right)_{y}+x \mathrm{Cd}^{2+}{ }_{(\mathrm{aq})}, \quad(x=0-17)
$$

The hydrated potassium ions reside in the interlamellar space and may, in turn, be quantitatively ion-exchanged with cetyl trimethy ammonium (CTA) to give $\mathrm{Cd}_{0-83} \mathrm{PS}_{3}(\mathrm{CTA})_{0-34}$.

$$
\mathrm{Cd}_{1-x} \mathrm{PS}_{3} \mathrm{~K}_{2 x}+\mathrm{CTAB}_{(\mathrm{aq})} \rightarrow \mathrm{Cd}_{1-x} \mathrm{PS}_{3}(\mathrm{CTA})_{2 x}+2 x \mathrm{~K}^{+}, \quad(x=0-17)
$$

Intercalation occurs with a lattice expansion of 26-5. . The observed expansion exceeds the length of the fully stretched CTA ion, $\sim 22 \AA^{21}$, indicating that within the galleries the intercalated surfactant ions adopt a tilted bilayer structure. It may be seen that grafting density is crucially important in deciding the organization of the intercalated surfactant ions in the galleries of $\mathrm{CdPS}_{3}$.

The system under investigation, CTA ions intercalated in $\mathrm{CdPS}_{3}$, offers the advantage that large lamellar crystals may easily be obtained. It has thus been possible to record the IR spectrum for different orientations of the electric dipole vector, $\mathbf{E}$, of the incident IR beam with respect to the interlamellar normal $\mathbf{C}^{*}$. These measurements in conjunction with the ${ }^{13}$ CMAS NMR studies have allowed us to establish the conformation of the intercalated surfactant, and the orientation of the alkyl chain with respect to the confining host lattice layers, as well as their variation with temperature.

\section{Experimental}

Cadmium thiophosphate, $\mathrm{CdPS}_{3}$, was prepared from the elements following the procedure reported in literature ${ }^{22}$. Cadmium metal powder, phosphorus and sulphur in stoichiometric amounts were sealed in quartz ampoules at $10^{-6}$ Torr and heated at $650^{\circ} \mathrm{C}$ for two weeks. Single crystals of $\mathrm{CdPS}_{3}$ were grown by chemical vapour transport using excess sulphur as a transporting agent. The charged end of the ampoule was maintained at $650^{\circ} \mathrm{C}$ and the cooler end at $600^{\circ} \mathrm{C}$. Platelet-like transparent crystals were obtained with a typical size $5 \times 5 \times 0-1 \mathrm{~mm}^{3}$. Cetyl trimethyl ammonium bromide (CTAB) (Loba Chem) was recrystalized from acetone.

The monolayer phase was synthesized by refluxing a weighed quantity of $\mathrm{CdPS}_{3}$ (crystals and powder) with $0-05 \mathrm{M}$ solution of cetyl trimethyl ammonium bromide in 0-1 M EDTA solution at $80^{\circ} \mathrm{C}$. The reaction was complete in two days and the intercalated product rinsed with distilled water. The intercalated compounds are stable in air. Complete ion-exchange was ascertained by the absence of the host $00 \mathrm{l}$ reflections and the appearance of new $00 \mathrm{l}$ reflections with lattice spacing of $11-3 \AA$. Cadmium ion stiochiometry was established by atomic absorption spectroscopy 
(Perkin-Elmer 4381) and that of the intercalated CTA ion by $\mathrm{CHN}$ analysis $(\mathrm{Cd}-$ $38 \cdot 29, \mathrm{C}-12 \cdot 22, \mathrm{~N}-0 \cdot 74, \mathrm{H}-2 \cdot 12 \%)$.

The bilayer phase was synthesized by a two-step process, in the first step, $\mathrm{CdPS}_{3}$ (powder and crystals) was treated with a $4 \mathrm{M}$ aqueous solution of potassium chloride in presence of $0.1 \mathrm{M}$ EDTA and $1 \mathrm{M} \quad \mathrm{K}_{2} \mathrm{CO}_{3} / \mathrm{KHCO}_{3}$ as buffer, to give $\mathrm{Cd}_{0 \cdot 83} \mathrm{PS}_{3} \mathrm{~K}_{0 \cdot 34}\left(\mathrm{H}_{2} \mathrm{O}\right)$. The compound has a lattice spacing of $9.4 \AA$, corresponding to a lattice expansion of $2.8 \AA$ as compared to pristine host $\mathrm{CdPS}_{3}$. The interlamellar potassium ions in $\mathrm{Cd}_{0-83} \mathrm{PS}_{3} \mathrm{~K}_{0-34}\left(\mathrm{H}_{2} \mathrm{O}\right)$ were further ion-exchanged with cetyl trimethyl ammonium (CTA) ions, by refluxing in an aqueous solution of $0.05 \mathrm{M} \mathrm{CTAB}$ at $50^{\circ} \mathrm{C}$ for $6 \mathrm{~h}$, to give $\mathrm{Cd}_{0.83} \mathrm{PS}_{3}(\mathrm{CTA})_{0-34}$. Completion of ion-exchange was ascertained from the disappearance of the $00 l$ reflection of $\mathrm{Cd}_{0 \cdot 83} \mathrm{PS}_{3} \mathrm{~K}_{0-34}\left(\mathrm{H}_{2} \mathrm{O}\right)$ in the X-ray diffraction pattern and the appearance of a new series of $00 \mathrm{l}$ reflections with a lattice spacing of $33 \AA$ corresponding to the formation of $\mathrm{Cd}_{0-83} \mathrm{PS}_{3}(\mathrm{CTA})_{0-34}(\mathrm{Cd}-29 \cdot 5, \mathrm{C}-23-95$, $\mathrm{N}-1 \cdot 53, \mathrm{H}-4 \cdot 51 \%)$.

Powder X-ray diffraction patterns were recorded on a Shimadzu-XD-D1 diffractometer using $\mathrm{CuK} \alpha$ radiation. Crystals were mounted flat on a sapphire disc, which occupied the same position as the regular sample holder on the X-ray goiniometer. ${ }^{13} \mathrm{CCP}-\mathrm{MAS}$ NMR were recorded on a Bruker DSX-300 solid state spectrometer at a Larmor frequency of $75.46 \mathrm{MHz}$ with a contact time of $1 \mathrm{~ms}$. The spectra were externally referenced to tetramethylsilane (TMS).

Infrared spectra of crystals were recorded in the spectral range $400-4000 \mathrm{~cm}^{-1}$ on a Bruker IFS55 spectrometer equipped with a polarizer accessory. The crystals were mounted on a hollow copper block and cooled using a CTI-Cryogenics closed cycle cryostat. Sample temperature could be varied from 300 to $40 \mathrm{~K}$. The cryostat was evacuated at $10^{-2}$ torr to prevent condensation on the crystals. The spectra for different orientations of the electric field vector, $\mathbf{E}$ of the incident IR with respect to the $\mathbf{C}^{*}$ axis of the crystals (the axis normal to the layers) was obtained using the arrangement described earlier ${ }^{9,23}$. In this arrangement the crystals are held in the sample block of the cryostat in such a way that the $\mathbf{C}^{*}$ axis of the platelet-like crystal is at an angle of $45^{\circ}$ with respect to the propagation vector of the incident IR beam. From a measurement of the IR spectrum for two different angles of polarization of the electric field vector, $\mathbf{E}$, the spectra for $\mathbf{E} \perp \mathbf{C}^{*}$ and $\mathbf{E} \mid \mathbf{C}^{*}$ could be recovered and subsequently, the spectrum for any orientation, $\phi$, of $\mathbf{E}$ with respect to $\mathbf{C}^{*}$ could be calculated.

\section{Results}

\section{$3.1 \quad X$-ray diffraction}

X-ray diffraction patterns of crystals of $\mathrm{Cd}_{0-93} \mathrm{PS}_{3}(\mathrm{CTA})_{0-14}$ and pristine $\mathrm{CdPS}_{3}$ showing the $00 \mathrm{l}$ Bragg reflections are shown in figure $2 \mathrm{a}$. The intercalate, $\mathrm{Cd}_{0-93} \mathrm{PS}_{3}(\mathrm{CTA})_{0-14}$, shows a lattice spacing of $11-3 \AA$ corresponding to a lattice expansion of $4-85 \AA$. The powder X-ray diffraction pattern of the intercalate $\mathrm{Cd}_{0-93} \mathrm{PS}_{3}(\mathrm{CTA})_{0-14}$ could be indexed in the same space group $C 2 / m$ as the host ${ }^{9}$ with lattice parameters $a=6 \cdot 18 \AA$, $b=10-71 \AA, c=11 \cdot 80 \AA$, and $\beta=107 \cdot 71^{\circ}$. The lattice parameters for the pure $\mathrm{CdPS}_{3}$ are $a=6 \cdot 22 \AA, b=10 \cdot 76 \AA, c=6 \cdot 87 \AA$ and $\beta=107 \cdot 58^{\circ}$.

The one-dimensional projected electron density of the intercalated compound, $\mathrm{Cd}_{0.93} \mathrm{PS}_{3}(\mathrm{CTA})_{0.14}$, was calculated from the Fourier transform of the X-ray $00 l$ reflections (figure $2 a$ ) and is shown in figure $2 b$ along with that of the host, $\mathrm{CdPS}_{3}$. The 


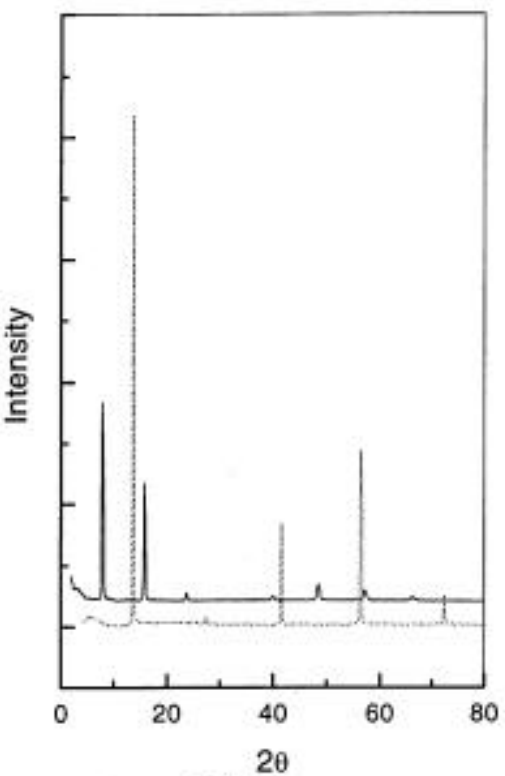

(a)

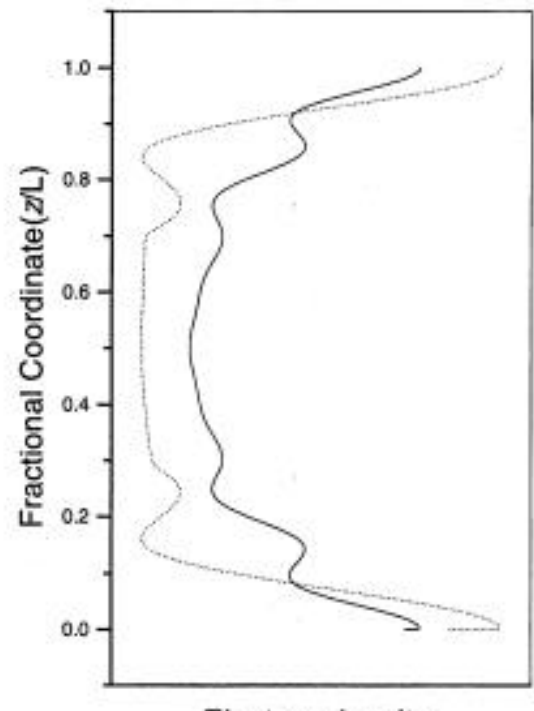

Electron density

(b)

Figure 2. (a) X-ray diffraction pattern showing the $00 l$ reflections of the intercalate $\mathrm{Cd}_{0-93} \mathrm{PS}_{3}(\mathrm{CTA})_{0 \cdot 14}$ (solid line) and the pristine host $\mathrm{CdPS}_{3}$ (dotted line) and (b) the corresponding projected one-dimensional electron density.

projected electron density of the intercalate $\mathrm{Cd}_{0-93} \mathrm{PS}_{3}(\mathrm{CTA})_{0-14}$, shows the layer structure identical to that of $\mathrm{CdPS}_{3}$ with the electron densities of the $\mathrm{S}$ atoms (peaks at $z / L=0.14$ and $z / L=0.86$ ) appearing at $1.58 \AA$ from the $\mathrm{Cd}$ atom. The additional electron density in the interlamellar region at $z / L=0.31$ and 0.69 are due to the intercalated CTA ion. The absence of density in the centre indicates that the methylene chains of the interlamellar surfactant molecules lie close to the surface of either the top or bottom layer, but not midway.

The X-ray diffraction patterns of crystals, of the intercalated bilayer compound $\mathrm{Cd}_{0.83} \mathrm{PS}_{3}(\mathrm{CTA})_{0.34}$, the starting compounds $\mathrm{Cd}_{0-83} \mathrm{PS}_{3} \mathrm{~K}_{0-34}\left(\mathrm{H}_{2} \mathrm{O}\right)$ and the pristine host $\mathrm{CdPS}_{3}$ are shown in figure 3. The interlayer spacing in the intercalated $\mathrm{Cd}_{0-83} \mathrm{PS}_{3}(\mathrm{CTA})_{0-34}$, as calculated from the X-ray $00 \mathrm{l}$ reflections, is $33 \AA$ corresponding to a lattice expansion of $26-5 \AA$ as compared to $\mathrm{CdPS}_{3}$. The observed lattice expansion cannot be accounted for by a monolayer arrangement of the intercalated surfactant ions even if the CTA ions were fully extended (all-trans) and the molecular axis of the methylene chains normal to the $\mathrm{Cd}_{0-83} \mathrm{PS}_{3}$ layers, since the length of the fully stretched CTA ion is $\sim 22 \AA$. This suggests that the intercalated surfactant adopts a tilted bilayer structure. In the absence of interdigitation, the tilt angle as calculated from the observed lattice expansion and the length of the CTA ion is $33^{\circ}$ with respect to the layers.

In the following sections we focus on the conformation and orientation of the methylene tail of the intercalated surfactant in the monolayer and bilayer phases. These are discussed separately. 


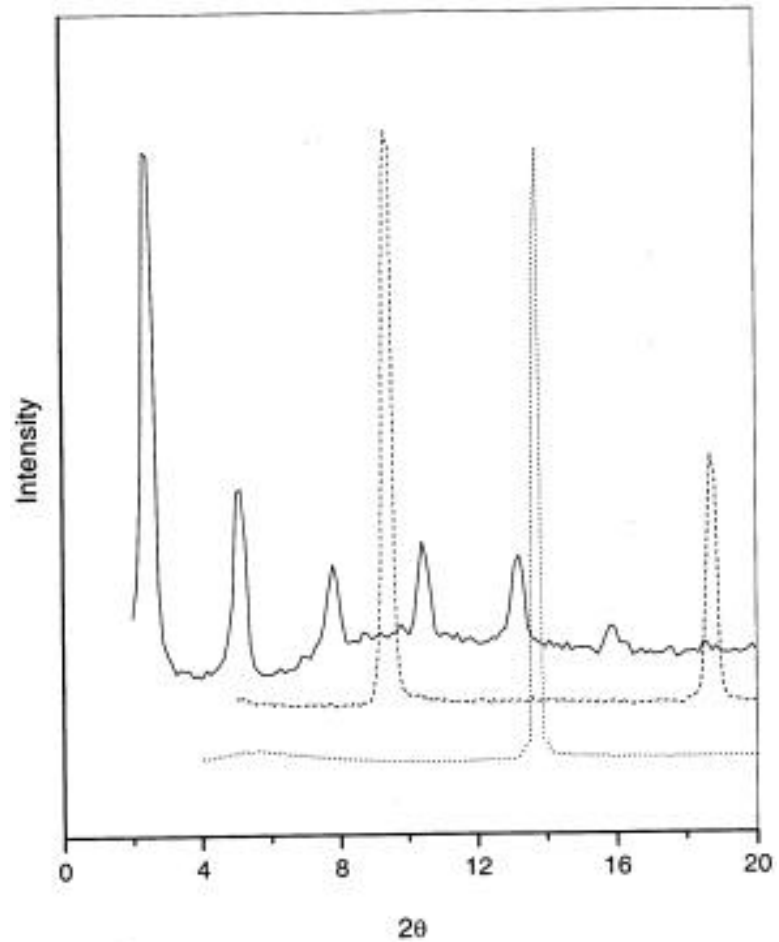

Figure 3. X-ray diffraction pattern showing the $00 l$ reflections of the intercalate $\mathrm{Cd}_{0-83} \mathrm{PS}_{3}(\mathrm{CTA})_{0-34}$ (solid line), $\mathrm{Cd}_{0-83} \mathrm{PS}_{3} \mathrm{~K}_{0-34}\left(\mathrm{H}_{2} \mathrm{O}\right)$ (dashed line) and the pristine host $\mathrm{CdPS}_{3}$ (dotted line).

\subsection{Intercalated surfactant monolayer, $\mathrm{Cd}_{0-93} \mathrm{PS}_{3}(\mathrm{CTA})_{0-14}$}

3.2a NMR spectroscopy: NMR spectroscopy has been widely used in the study of surfactant systems such as micelles, liquid crystals and micro emulsions. ${ }^{13} \mathrm{C} N \mathrm{NR}$ has also been used to probe the conformation and dynamics of surfactant molecules at interfaces. ${ }^{13} \mathrm{C}$ NMR chemical shift differences have been used to characterize chain conformation as well as conformational heterogeneity ${ }^{24}$. It has been shown that the degree of shielding of a carbon atom in a methylene chain depends on the relative population of trans and gauche conformers, with the trans conformer giving rise to a downfield shift ${ }^{25}$.

${ }^{13} \mathrm{C}$ CP-MAS NMR spectra of solid CTAB and the intercalate $\mathrm{Cd}_{0 \cdot 93} \mathrm{PS}_{3}(\mathrm{CTA})_{0-14}$ are shown in figure 4 . The numbering of the carbons, along with their assignments, are also shown. The assignments are based on the reported values for crystalline CTAB ${ }^{26}$. For solid CTAB, seven carbon resonances are observed which are in order of increasing downfield shift, $\mathrm{C}_{1}, \mathrm{C}_{\mathrm{N}}, \mathrm{C}_{14}, \mathrm{C}_{2}, \mathrm{C}_{16}, \mathrm{C}_{3}$ and $\mathrm{C}_{15}, \mathrm{C}_{4}-\mathrm{C}_{13}$. In the case of the intercalate, the peaks for $\mathrm{C}_{2}$ and $\mathrm{C}_{14}$ are no longer resolved and appear merged with the resonance for the $\mathrm{C}_{4}-\mathrm{C}_{13}$ carbon atoms. The most prominent difference is in the position of the $\mathrm{C}_{1}$ carbon atom resonance, which is shifted considerably downfield in the intercalated compound. The resonances of the other middle carbons are also shifted down-field but not to the same extent. The resonances of $C_{N}$ and $C_{16}$ are almost unaffected. Since in crystalline CTAB the methylene chain has an all trans 


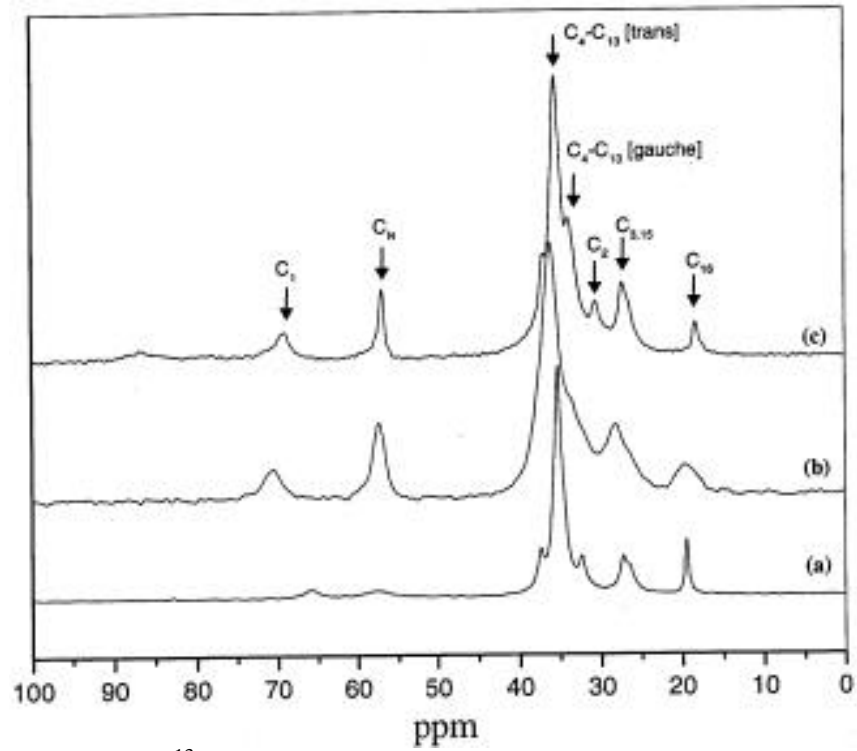

Figure 4. ${ }^{13} \mathrm{C}$ CP-MAS NMR spectra of (a) crystalline CTAB, (b) the monolayer intercalate $\mathrm{Cd}_{0 \cdot 93} \mathrm{PS}_{3}(\mathrm{CTA})_{0 \cdot 14}$ and (c) the bilayer intercalate $\mathrm{Cd}_{0 \cdot 83} \mathrm{PS}_{3}(\mathrm{CTA})_{0 \cdot 34}$. The assignments along with the numbering of the carbon atoms is shown.

conformation these results indicate a similar conformation for the intercalated CTA ion, but with an enhanced trans conformation for the $\alpha$ carbon $\left(\mathrm{C}_{1}\right)$.

It is also interesting to note that the resonance peaks for $C_{N}$ and $C_{1}$ in the CP-MAS NMR (figure 4) are considerably narrower and more intense for the intercalate compared to solid CTAB, whereas the peak for $\mathrm{C}_{16}$ is broader for the intercalate. The spectra were recorded under identical condition. This suggests decreased mobility for the $\alpha$ carbon $\left(\mathrm{C}_{1}\right)$ and for the $-\mathrm{N}^{+}\left(\mathrm{CH}_{3}\right)_{3}$ 'head' group for the intercalated CTA as compared to solid CTAB, but increased mobility for the 'tail' methyl carbon $\left(\mathrm{C}_{16}\right)$ in the intercalate. This is a consequence of the coulumbic interaction of the positively charged head group of the surfactant with the negatively charged $\mathrm{Cd}_{0-93} \mathrm{PS}_{3}$ layer.

3.2b Vibrational spectroscopy: Vibrational spectroscopy has been used extensively to probe the conformation and organization of alkyl chain assemblies ${ }^{27-30}$. The frequency and line-shape of the stretching and bending vibrational modes of the $\mathrm{CH}_{2}$ and $\mathrm{CH}_{3}$ groups are sensitive to the gauche to trans conformer ratio of the alkyl chains. The methylene stretching modes, for example, shift from lower frequencies characteristic of the highly ordered all-trans conformation to higher frequencies and increased linewidth as the number of gauche conformers in the chain increases ${ }^{29,30}$. For an all-trans alkyl chain, as in the case of crystalline $n$-alkanes, the symmetric and anti-symmetric stretching frequencies are typically in the range 2846-2849 and 2916-2919 $\mathrm{cm}^{-1}$ respectively. With increasing number of gauche conformers this ranges shifts to 2854 2856 and $2924-2928 \mathrm{~cm}^{-1}$. The infrared spectral peak positions and assignments of the $\mathrm{Cd}_{0.93} \mathrm{PS}_{3}(\mathrm{CTA})_{0.14}$ are given in table 1 along with the corresponding assignment for 
Table 1. Infrared frequencies for the monolayer, $\mathrm{Cd}_{0-{ }_{93}} \mathrm{PS}_{3}(\mathrm{CTA})_{0.14}$, bilayer phase, $\mathrm{Cd}_{0.83} \mathrm{PS}_{3}(\mathrm{CTA})_{0.34}$ and crystalline $\mathrm{CTAB}$ along with the assignments.

\begin{tabular}{|c|c|c|c|}
\hline $\begin{array}{l}\text { Crystalline } \\
\text { CTAB } \\
\left(\mathrm{cm}^{-1}\right)\end{array}$ & $\begin{array}{l}\text { Monolayer phase } \\
\mathrm{Cd}_{0-93} \mathrm{PS}_{3}(\mathrm{CTA})_{0-14} \\
\left(\mathrm{~cm}^{-1}\right)\end{array}$ & $\begin{array}{c}\text { Bilayer phase } \\
\mathrm{Cd}_{0 \cdot 83} \mathrm{PS}_{3}(\mathrm{CTA})_{0 \cdot 34} \\
\left(\mathrm{~cm}^{-1}\right)\end{array}$ & Assignment \\
\hline $3030(w)]$ & $3048(m)$ & & \\
\hline $3016(m)$ & $3030(\mathrm{~m})$ & & $\mathrm{N}^{+}-\left(\mathrm{CH}_{3}\right) \mathrm{C}-\mathrm{H}$ asym. stretch \\
\hline $\begin{array}{l}3009(s h) \\
2972(s h) \\
2960(s h)\end{array}$ & & $3010(\mathrm{~m})$ & $\mathrm{N}^{+}-\left(\mathrm{CH}_{3}\right) \mathrm{C}-\mathrm{H}$ sym. stretch \\
\hline $\begin{array}{l}2945(\mathrm{~m}) \\
2918(\mathrm{~s}) \\
2872(\mathrm{~m})\end{array}$ & $\begin{array}{l}2937(m) \\
2918(s)\end{array}$ & $\begin{array}{l}2952(s h) \\
2920(s)\end{array}$ & $\begin{array}{l}\mathrm{CH}_{3} \mathrm{C}-\mathrm{H} \text { asym. stretch } \\
\mathrm{CH}_{2} \text { antisym. stretch } \\
\mathrm{CH}_{3} \mathrm{C}-\mathrm{H} \text { sym. stretch }\end{array}$ \\
\hline $2848(s)$ & $2846(s)$ & $\begin{array}{l}2850(s) \\
1623(s)\end{array}$ & $\begin{array}{l}\mathrm{CH}_{2} \text { sym. stretch } \\
\mathrm{H}_{2} \mathrm{O} \text { bending }\end{array}$ \\
\hline $1487(s)$ & $1484(s)$ & $1484(s h)$ & $\mathrm{N}^{+} \mathrm{CH}_{3}$ bending \\
\hline $\left.\begin{array}{l}1473(s) \\
1462(s)\end{array}\right\}$ & $1465(s)$ & $1467(s)$ & $\mathrm{CH}_{2}$ scissoring \\
\hline $\begin{array}{l}1373(w) \\
964(s)\end{array}$ & $1378(m)$ & $\begin{array}{l}1376(m) \\
964(s)\end{array}$ & $\mathrm{CH}_{3}$ sym. bending \\
\hline $912(s)$ & $905(m)$ & $\begin{array}{l}957(s) \\
906(m)\end{array}$ & $\mathrm{C}-\mathrm{N}^{+}$stretching \\
\hline $\begin{array}{l}729(s) \\
719(m)\end{array}$ & & $721(s)$ & $\mathrm{CH}_{2}$ rocking \\
\hline
\end{tabular}

solid CTAB. In the subsequent discussion, however, we shall focus only on the region of the methylene stretching frequencies which are known to be sensitive to the chain conformation.

The IR spectrum of crystals of $\mathrm{Cd}_{0-93} \mathrm{PS}_{3}(\mathrm{CTA})_{0 \cdot 14}$ for two orientations of the incident electric field vector $(\mathbf{E})$ with respect to the interlamellar normal $\left(\mathbf{C}^{*}\right), \mathbf{E} \perp \mathbf{C}^{*}$ and $\mathbf{E} \| \mathbf{C}^{*}$, were recorded at various temperatures using the arrangement described in the experimental section. The spectra of crystals of $\mathrm{Cd}_{0-93} \mathrm{PS}_{3}(\mathrm{CTA})_{0-14}$ for $\mathbf{E} \perp \mathbf{C}^{*}$ as a function of temperature are shown in the figure 5. The positions of the symmetric $\left(2846 \mathrm{~cm}^{-1}\right)$ and antisymmetric $\left(2918 \mathrm{~cm}^{-1}\right)$ methylene $\mathrm{C}-\mathrm{H}$ stretching modes indicates that the intercalated surfactant alkyl chains adopt an essentially all-trans conformation; defects (kinks), if any due to the presence of gauche conformer are few in number.

The most striking change in the spectrum on lowering the temperature is the change in the ratio of the intensities of the antisymmetric methylene $\mathrm{C}-\mathrm{H}$ stretching mode $\left(I v_{\mathrm{as}}\right)$ to that of the symmetric mode $\left(I v_{\mathrm{s}}\right)$. The intensity ratio, $I \boldsymbol{V}_{\mathrm{as}} / I \boldsymbol{V}_{\mathrm{s}}$, decreases with decreasing temperature and by $40 \mathrm{~K}$ the intensity of the symmetric stretch $\left(\boldsymbol{I}_{\mathrm{s}}\right)$ is considerably greater than that for the antisymmetric mode.

The IR spectra of $\mathrm{Cd}_{0-93} \mathrm{PS}_{3}(\mathrm{CTA})_{0-14}$ crystals for $\mathbf{E} \mid \mathbf{C}^{*}$ at $300 \mathrm{~K}$ and $40 \mathrm{~K}$ are shown in figure 6. The symmetric and anti-symmetric $\mathrm{CH}_{2}$ modes appear at the same position as in the $\mathbf{E} \perp \mathbf{C}^{*}$ spectra. The intensity ratio of the antisymmetric to symmetric stretching modes is, however, reversed. In the $\mathbf{E} \mid \mathbf{C}^{*}$ it is the intensity $I \boldsymbol{V}_{\mathrm{as}}$ which is greater than $I v_{\mathrm{s}}$ and in fact the intensity ratio $I v_{\mathrm{as}} / I v_{\mathrm{s}}$ increases with decreasing temperature. At low temperature, a peak at $2937 \mathrm{~cm}^{-1}$ is clearly resolved in the $\mathbf{E} \mid \mathbf{C}^{*}$ spectra. It is difficult to unambiguously assign this peak, since a number of different 


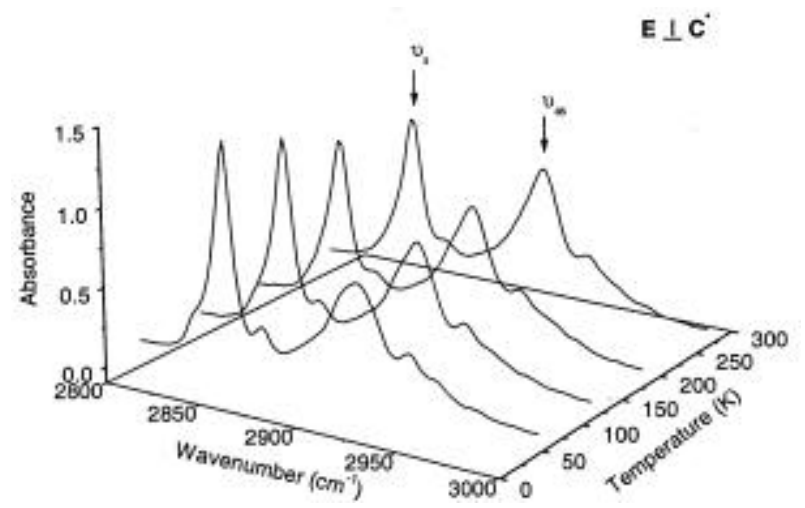

Figure 5. IR spectra of crystal of $\mathrm{Cd}_{0-93} \mathrm{PS}_{3}(\mathrm{CTA})_{0^{*-14}}$ recorded with the electric dipole of the incident IR beam $(\mathbf{E})$ perpendicular to the interlamellar normal $\left(\mathbf{C}^{*}\right)$, as a function of temperature.

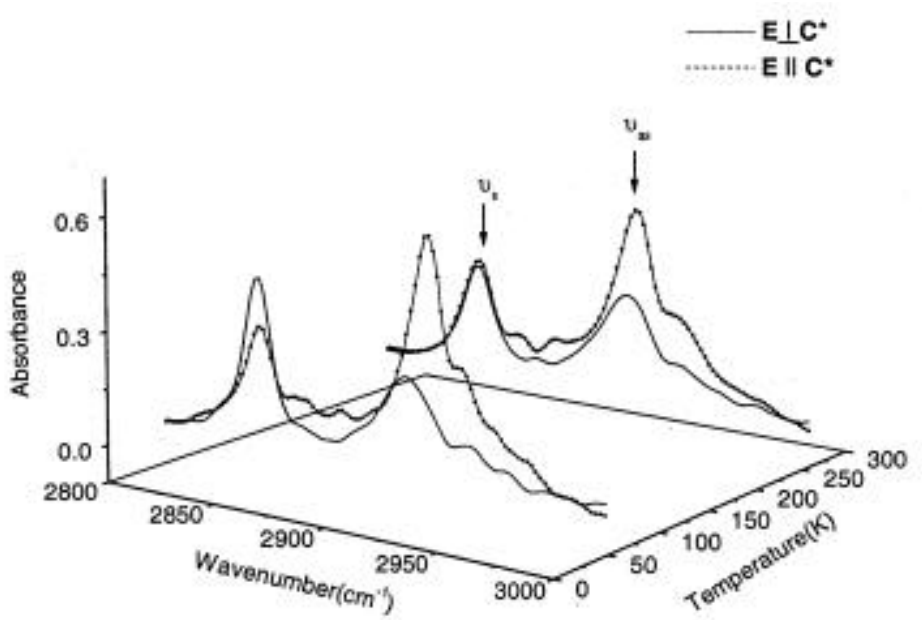

Figure 6. IR spectra of crystal of $\mathrm{Cd}_{0-93} \mathrm{PS}_{3}(\mathrm{CTA})_{0 \cdot 14}$ at 300 and $40 \mathrm{~K}$ for two orientations, $\mathbf{E} \perp \mathbf{C} *$ (solid line) and $\mathbf{E} \| \mathbf{C}^{*}$ (dotted line).

modes are known to appear in this region ${ }^{30}$. The low temperature spectra for the two orientations, $\mathbf{E} \perp \mathbf{C}^{*}$ and $\mathbf{E} \mid \mathbf{C}^{*}$, are compared in figure 6 . The absence of any significant change either in the line-width or position of the methylene stretching modes in the $\mathbf{E} \mid \mathbf{C}^{*}$ as well as the $\mathbf{E} \perp \mathbf{C}^{*}$ spectra on cooling indicates that the trans/gauche ratio does not change. Since stretching modes of the gauche conformers appear at higher frequencies as compared to the trans, an increase in the gauche/trans ratio would lead to a shift in the position of the methylene stretching modes to higher frequencies or at least to a change in line width. The absence of either indicates that the conformation of the methylene 'tail' of the intercalated CTA ion is essentially all-trans at all temperatures. The intensity ratio $N_{\mathrm{as}} / \boldsymbol{v}_{\mathrm{s}}$, however, is higher in the $\mathbf{E} \perp \mathbf{C}^{*}$ spectrum and increases with decreasing temperature, whereas in the $\mathbf{E} \mid \mathbf{C}^{*}$ spectrum, this ratio is lower and decreases with decreasing temperature. 
The implication of these results may be understood by considering the direction of the transition moment dipole vector of the antisymmetric and symmetric stretch, $\mu_{\mathrm{as}}$ and $\mu_{\mathrm{s}}$, of the methylene groups in an all-trans chain. The transition dipole vectors of the antisymmetric methylene $\mathrm{C}-\mathrm{H}$ stretch and that for the symmetric methylene $\mathrm{C}-\mathrm{H}$ stretch are orthogonal to each other and also perpendicular to the molecular axis (figure 7). The transition moment for the symmetric stretch, $\mu_{s}$, lies in the molecular plane, whereas for the antisymmetric stretch, $\mu_{\mathrm{as}}$, it lies perpendicular to the molecular plane.

The fact that for the $\mathbf{E} \perp \mathbf{C}^{*}$ spectra the intensity $\boldsymbol{V}_{\mathrm{s}}$ is greater than $\boldsymbol{V}_{\mathrm{as}}$, whereas in the $\mathbf{E} \mid \mathbf{C}^{*}$ spectra it is the opposite, implies that a large section of the molecular plane of the trans methylene chain is parallel to the confining $\mathrm{Cd}_{0-93} \mathrm{PS}_{3}$ layers. The observed temperature variation then requires that increasingly larger sections of the molecular plane of the methylene 'tail' of the surfactant molecule align parallel to the layers with decreasing temperature. Even at the lowest temperature, however, the molecular plane of the surfactant is not aligned parallel to the layers over the entire length of the alkyl chain. If this were so, then $I v_{\text {as }}$ should vanish for $\mathbf{E} \perp \mathbf{C}^{*}$ and $I v_{\mathrm{s}}$ for $\mathbf{E} \mid \mathbf{C}^{*}$, which is not observed. This implies the presence of at least one 'kink', with the molecular plane of the alkyl chain aligned parallel with respect to the layers only on one side of the 'kink'. With decreasing temperature the 'kink' moves outwards towards the end of the chain, leaving larger and larger sections of the molecular plane aligned with respect to the layers. This is shown schematically in figure 8 .

These results are the first spectroscopic observations to show that even in the absence of intermolecular interactions, weak adhesive interactions are sufficient to cause methylene chains to adopt an all-trans configuration in the vicinity of a confining surface. The surface also orients the molecular plane of the all-trans methylene chain parallel to the layers. With decreasing temperature, equivalent to strengthening the adhesive interactions, increasingly larger sections of the molecular plane align parallel to the surface of the gallery walls (figure 8). Such an alignment would lead to greater contact, allowing all methylene units to interact with the surface, thus maximizing the adhesive interaction.

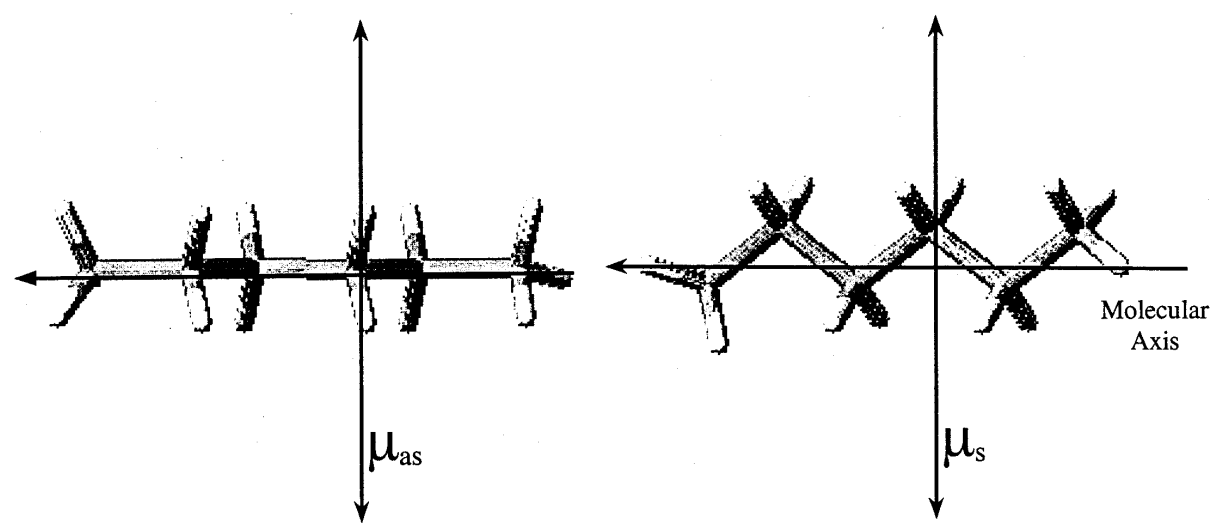

Figure 7. The direction of the transition dipole vectors of the methylene antisymmetric $\left(v_{\mathrm{as}}\right)$ and symmetric $\left(v_{\mathrm{s}}\right)$ stretching modes with respect to the molecular axis as well as the molecular plane. In the panel on the left, the molecular plane is perpendicular to the plane of the paper and on the right the molecular plane is coplanar. 
(a)

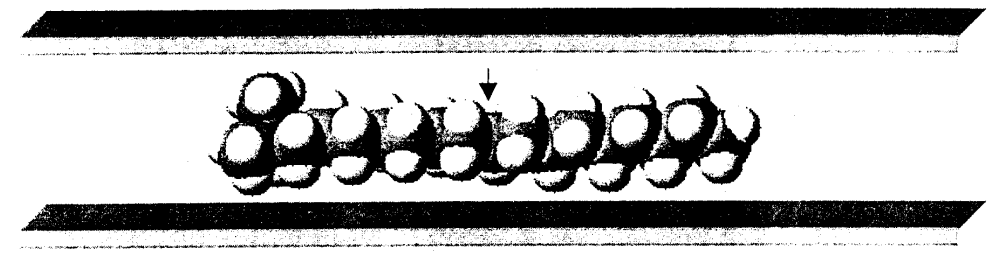

(b)

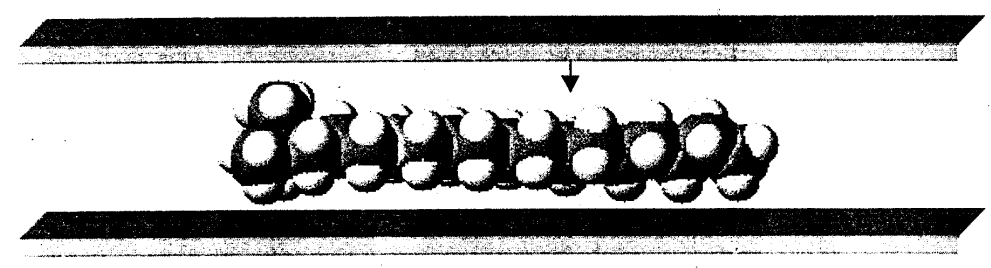

(c)

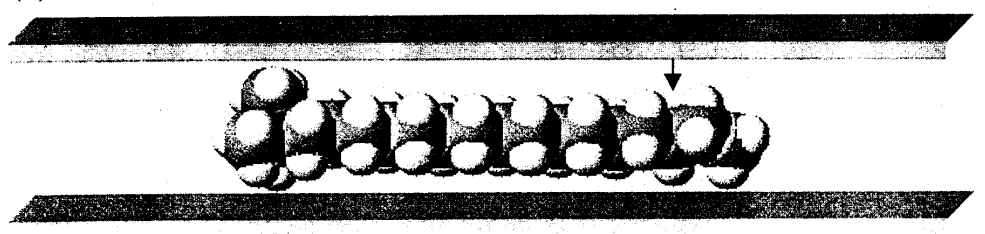

Figure 8. Cartoon depicting the conformation and alignment of the methylene 'tail' of the confined surfactant. With decreasing temperature, (a)-(c), increasingly larger sections of the molecular plane of the methylene chain (to the left of the arrow) align parallel to the confining surface.

It is interesting to speculate on the implications of these results for a molecular level understanding of how a lubricant functions. Films of surfactants play an important role in dry boundary-layer lubrication in many applications such as micromotor and harddisk drives. Our results indicate that even at sub-monolayer concentrations long-chain hydrocarbons with a 'sticky' end can be effective in reducing friction. By lying as aligned flat, rigid rods on the surface, contact between rubbing surfaces would be minimized in addition to making it difficult for the lubricating surfactant to be sheared away from the surface.

\subsection{Intercalated surfactant bilayer, $\mathrm{Cd}_{0 \cdot 83} \mathrm{PS}_{3}(\mathrm{CTA})_{0 \cdot 34}$}

3.3a NMR spectroscopy: The ${ }^{13} \mathrm{CCP}-\mathrm{MAS}$ NMR spectra of the intercalated bilayer phases of $\mathrm{Cd}_{0.83} \mathrm{PS}_{3}(\mathrm{CTA})_{0.34}$ is shown in figure 4 , along with the spectrum of crystalline CTAB. The assignments are based on the reported values for CTAB. A comparison of the ${ }^{13} \mathrm{CNMR}$ spectra of the intercalate $\mathrm{Cd}_{0-83} \mathrm{PS}_{3}(\mathrm{CTA})_{0-34}$ and pure $\mathrm{CTAB}$ shows that the resonance position of most of the $\mathrm{C}$ atoms are not significantly shifted except for the $C_{1}$ atom. In the intercalated compounds, $C_{3}$ and $C_{15}$ are not resolved as separate resonances; $\mathrm{C}_{14}$, too, is poorly resolved. The intercalated bilayer phase, however, shows an additional resonance at $34 \mathrm{ppm}$. 
The $\mathrm{C}_{1}$ atom resonance of the intercalated compounds is considerably downfieldshifted as compared to crystalline CTAB. This indicates an enhanced trans conformation for the $\mathrm{C}_{1}$ atom in bilayer phase of the intercalate $\mathrm{Cd}_{0.83} \mathrm{PS}_{3}(\mathrm{CTA})_{0-34}$. A major difference in the CP-MAS ${ }^{13} \mathrm{C}$ spectrum of pure $\mathrm{CTAB}$ and $\mathrm{Cd}_{0-83} \mathrm{PS}_{3}(\mathrm{CTA})_{0-34}$ is that the $C_{N}$ and $C_{1}$ resonances are considerably narrower and more intense in the intercalated compounds. This suggests decreased mobility of the $\alpha$ carbon $\left(\mathrm{C}_{1}\right)$ and the $\mathrm{N}^{+}\left(\mathrm{CH}_{3}\right)_{3}$ 'head' group for the CTA ion in the intercalated bilayer as compared to solid CTAB. This observation is similar to that for the intercalated monolayer phase.

The appearance of two peaks for the $\mathrm{C}_{4}-\mathrm{C}_{13}$ resonance in the intercalated bilayer and its absence in crystalline CTAB indicates greater conformational heterogeneity in the former. The downfield resonance (35-6 ppm, figure 4) is assigned to methylene units in a trans configuration; its position is identical to that in crystalline CTAB. The upfield resonance (34 ppm, figure 4) is assigned to methylene carbons in a gauche configuration. This assignment is similar to that of a recent report on the ${ }^{13} \mathrm{C} N M R$ of surfactant molecules intercalated in clays, where an additional upfield resonance was observed. This had been assigned to a disordered conformation ${ }^{24}$.

3.3b Vibrational spectroscopy: The peak position in the IR spectrum of $\mathrm{Cd}_{0.83} \mathrm{PS}_{3}(\mathrm{CTA})_{0-34}$ along with their assignments is given in table 1 . The IR spectra of the methylene stretching region in crystals of the intercalate $\mathrm{Cd}_{0.83} \mathrm{PS}_{3}(\mathrm{CTA})_{0-34}$ recorded at room temperature for the two orientations $\mathbf{E} \perp \mathbf{C}^{*}$ and $\mathbf{E} \mid \mathbf{C}^{*}$ are shown in figure 9. On cooling the crystals, neither the position nor the line-width of these bands

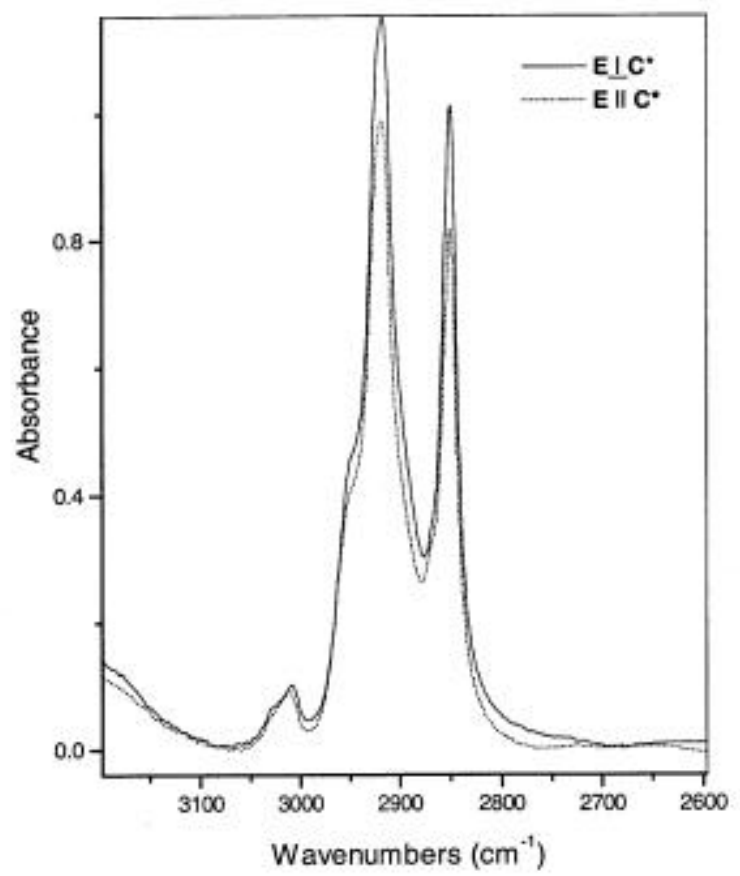

Figure 9. FT-IR spectrum, in the $\mathrm{C}-\mathrm{H}$ stretching region, of $\mathrm{Cd}_{0 \cdot 83} \mathrm{PS}_{3}(\mathrm{CTA})_{0.34}$ recorded for two orientations of the electric field vector $(\mathbf{E})$ of the incident IR beam with respect to the interlamellar normal $\left(\mathbf{C}^{*}\right), \mathbf{E} \perp \mathbf{C}^{*}$ (dotted line) and $\mathbf{E} \| \mathbf{C}^{*}$ (solid line). 
shows any perceptible change (the significance of the orientation dependence of the spectrum will be discussed in the next section). The spectra shows two strong bands at 2850 and $2919 \mathrm{~cm}^{-1}$ corresponding to the symmetric and antisymmetric stretching modes of the methylene, $-\left(\mathrm{CH}_{2}\right)_{n}-$, groups. The frequencies of the symmetric and antisymmetric stretching modes of the methylene groups are slightly higher than those for the corresponding modes in the all-trans crystalline $n$-alkanes, but are still considerably lower than the observed values in the disordered liquid-phase of the $n$-alkanes. This suggests that the methylene chains of the intercalated surfactant adopt an essentially all-trans conformation; gauche conformers are present but their population is small. The presence of the latter is also reflected in the greater line widths of the symmetric and antisymmetric methylene stretching modes observed for the intercalate, 16 and $30 \mathrm{~cm}^{-1}$ respectively, as compared to the reported values for crystalline $n$-alkanes, $6-9 \mathrm{~cm}^{-1}$ and $8-11 \mathrm{~cm}^{-1}$.

3.3c Orientation of the methylene chain: The orientation dependent IR spectra in the $\mathrm{C}-\mathrm{H}$ stretching region of crystals of $\mathrm{Cd}_{0 \cdot{ }_{3}} \mathrm{PS}_{3}(\mathrm{CTA})_{0.34}$ has been used to estimate the tilt angle of the intercalated surfactant methylene 'tail' with respect to the layers. In the subsequent discussion we ignore the presence of the gauche conformers and consider the conformation of the methylene 'tail' of the intercalated CTA ion as alltrans. The tilt angle, $\theta$, is the angle the molecular axis of the all trans methylene chain

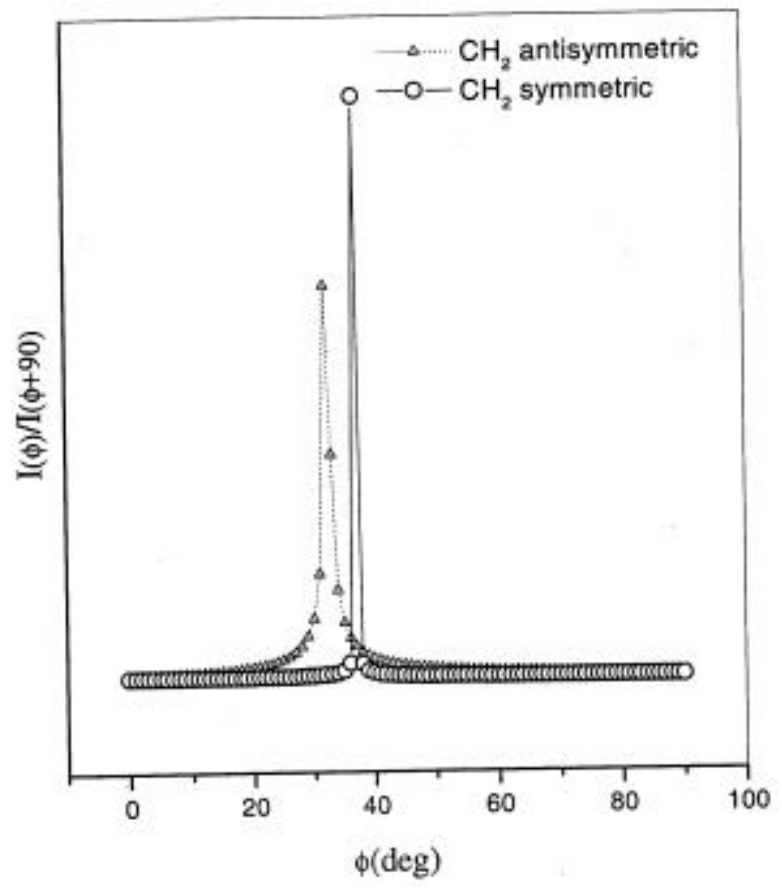

Figure 10. A plot of the dichroic ratio $[I(\phi) / I(\phi+90)]$ as a function of $\phi$ for the methylene symmetric and antisymmetric stretching modes of $\mathrm{Cd}_{0.83} \mathrm{PS}_{3}(\mathrm{CTA})_{0.34} . \phi$ is the angle the electric dipole of the incident IR beam (E) makes with the interlamellar normal $\left(\mathbf{C}^{*}\right)$. 
makes with the $\mathrm{Cd}_{0.83} \mathrm{PS}_{3}$ layer. From the spectra for the two orientations $\mathbf{E} \perp \mathbf{C}^{*}$ and $\mathbf{E} \mid \mathbf{C}^{*}$ (figure 9), the spectrum for different angles, $\phi$, of the electric field vector of the incident IR radiation (E) with respect to the interlamellar normal $\left(\mathbf{C}^{*}\right)$, may be calculated. The dichroic ratios $I_{\phi} / I_{\phi+90}$ for the symmetric $\left(2850 \mathrm{~cm}^{-1}\right)$ and antisymmetric $\left(2920 \mathrm{~cm}^{-1}\right)$ methylene stretching modes of $\mathrm{Cd}_{0.83} \mathrm{PS}_{3}(\mathrm{CTA})_{0.34}$ have been plotted as a function of $\phi$ in figure 10. $I(\phi)$ is the intensity of the vibrational mode for an angle $\phi$. The dichroic ratio for the symmetric and antisymmetric methylene $\mathrm{C}-\mathrm{H}$ stretching modes in $\mathrm{Cd}_{0.83} \mathrm{PS}_{3}(\mathrm{CTA})_{0.34}$ peak at $37^{\circ}$ and $32^{\circ}$ respectively.

The dichroic ratio for a vibrational mode will peak at a value $\phi$ for which the electric field vector of the incident IR beam is parallel to the transition dipole moment of that mode. For an all-trans methylene chain the transition dipole moment of the methylene symmetric stretching modes $\left(\boldsymbol{\mu}_{\mathbf{s}}\right)$ are orthogonal to the molecular axis but lie in the molecular plane of the trans methylene chain, whereas that of the antisymmetric stretching modes $\left(\mu_{\mathrm{ss}}\right)$ are orthogonal to the molecular axis and also to the molecular plane (figure 7). The fact that the dichroic for these two modes in $\mathrm{Cd}_{0-83} \mathrm{PS}_{3}(\mathrm{CTA})_{0-34}$ peak at approximately the same values of $\phi$ implies that the molecular plane of the alltrans methylene chain of the intercalated surfactant has no fixed orientation with respect to the $\mathbf{C}^{*}$ axis. The transition dipole moment of the symmetric and antisymmetric stretching modes of the methylene groups lie in a plane perpendicular to the molecular axis. The angle at which the dichroic ratio peaks is therefore the angle this plane makes with the interlamellar normal. From the plot of the dichroic ratio of symmetric stretching mode as a function of $\phi$ (figure 10) the tilt angle of the intercalated methylene chain in $\mathrm{Cd}_{0.83} \mathrm{PS}_{3}(\mathrm{CTA})_{0.34}$ is $37^{\circ}$. The value determined from the dichroic ratio of the antisymmetric stretching mode is $32^{\circ}$. These values are almost identical to that calculated from the observed X-ray lattice expansion, $33^{\circ}$, assuming that the methylene chains of the intercalated CTA ions are fully extended (all-trans) and the complete absence of interdigitation of the intercalated surfactant bilayer.

3.2d Localized methylene wagging modes: The values of the methylene stretching frequencies of $\mathrm{Cd}_{0-83} \mathrm{PS}_{3}(\mathrm{CTA})_{0-34}$ indicate that gauche configurations may be present; their population, however, would be small. To identify the conformationally disordered configurations, the methylene wagging region has been examined in greater detail. Methylene wagging modes in the IR spectrum of $n$-alkanes in the region 1300$1400 \mathrm{~cm}^{-1}$ are known to exhibit peaks with characteristic frequencies for different conformational sequences or high energy rotamers. These bands are specific to localized structures that contain a gauche bond ${ }^{31}$. For example, a peak at $1341 \mathrm{~cm}^{-1}$ indicates a penultimate bond oriented such that the terminal methyl group is in gauche conformation relative to the methylene group, three carbon atoms away. A peak at $1354 \mathrm{~cm}^{-1}$ is due to two adjacent gauche bonds and a peak at $1368 \mathrm{~cm}^{-1}$ arises from a gauche-trans-gauche sequence. Since these are localized modes, the area under the peaks is proportional to the probability of occurrence of the specific bond sequence ${ }^{32}$. The methyl umbrella deformation band, which appears at $1377 \mathrm{~cm}^{-1}$, is taken as the internal standard and the spectra in this region normalized with respect to this band. The population of specific conformational sequences may then be obtained from the normalized intensities. The spectrum of the intercalate $\mathrm{Cd}_{0.83} \mathrm{PS}_{3}(\mathrm{CTA})_{0-34}$, at $300 \mathrm{~K}$, normalized with respect to $1377 \mathrm{~cm}^{-1}$ band is shown in figure 11a (filled circles). The spectrum shows bands at $1341 \mathrm{~cm}^{-1}, 1353 \mathrm{~cm}^{-1}, 1368 \mathrm{~cm}^{-1}$ assignable to the end gauche, double gauche and ' $g-t-g$ ' sequence respectively. The spectrum can be fitted 

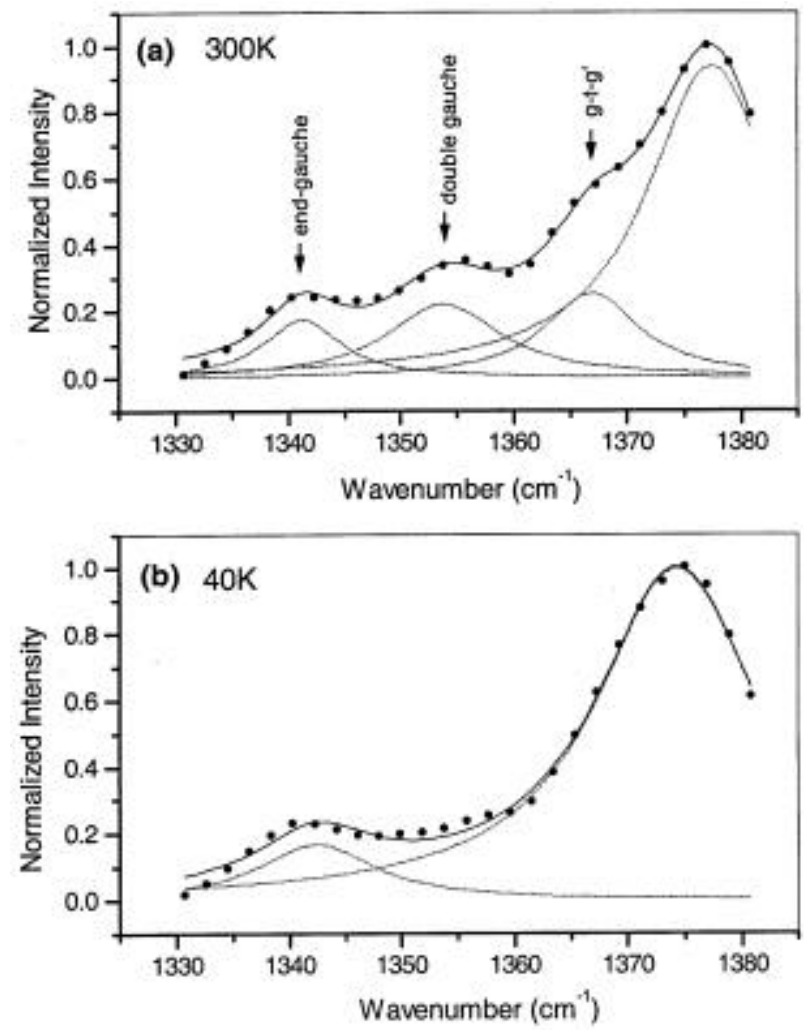

Figure 11. FT-IR spectrum in the methylene wagging region of $\mathrm{Cd}_{0.83} \mathrm{PS}_{3}(\mathrm{CTA})_{0.34}$ at (a) $300 \mathrm{~K}$ and (b) $40 \mathrm{~K}$. Closed circles are experimental data points. The solid line is a fit to the experimental data and the dotted lines, the individual Lorenztian components.

by weighted sum of the individual sequences assuming a Lorenztian line-shape for each component. Such a fit (solid line) along with the individual components (dotted lines) is also shown in figure 11. The relative population of the high energy conformer sequences may be estimated from the integrated intensities of the components in the fit. The ratio of the population of the end-gauche to double gauche to $g-t-g$ conformers is $1: 2: 2$. On lowering the temperature, these high energy rotamer states, except for the end-gauche $\left(1341 \mathrm{~cm}^{-1}\right)$, disappear. The absence peaks corresponding to double gauche and $g-t-g$ ' sequences is clearly evident in figure $11 \mathrm{~b}$. The concentration of end-gauche conformation, however, shows practically no change between 300 and $40 \mathrm{~K}$. In principle, the thermodynamic parameters associated with the high-energy rotamers could have been determined from measurement of their intensities at different temperatures. The poor spectral quality at intermediate temperatures, however, prevented such an exercise. 
3.3e Progression bands of the delocalized modes of the methylene chain: The disappearance of the higher energy rotamer states at lower temperatures is further manifested in the IR wagging and rocking-twisting band progression, which appears as a progressive series of moderate intensity in the spectrum of $\mathrm{Cd}_{0.83} \mathrm{PS}_{3}(\mathrm{CTA})_{0.34}$ in the regions $1370-1170 \mathrm{~cm}^{-1}$ and $1050-700 \mathrm{~cm}^{-1}$ respectively ${ }^{32}$. Conformational order in alkyl chains causes coupling of the methylene vibrational modes. The vibrational spectra of ordered alkyl chain systems have been analysed based on dispersion curves by plotting the frequencies $\mathrm{v}$ as a function of the phase angle $\phi$ between neighbouring methylene units. These have been compared with the theoretical dispersion curves for methylene vibrational modes obtained by normal coordinate analysis of an infinite polymethylene chain $^{33}$.

Vibrational modes in an all-trans methylene chain are described through a coupled oscillator model in which the phase difference between adjacent oscillators is given by $^{33}$,

$$
\varphi_{k}=k \pi(n+1), \quad[k=1,2,3, \ldots, n],
$$

where $n$ is the number of oscillators in the chain. The progression bands appearing in the spectrum are analysed by assigning a $k$ value after identifying the particular mode to which it belongs ${ }^{11}$.

(a)

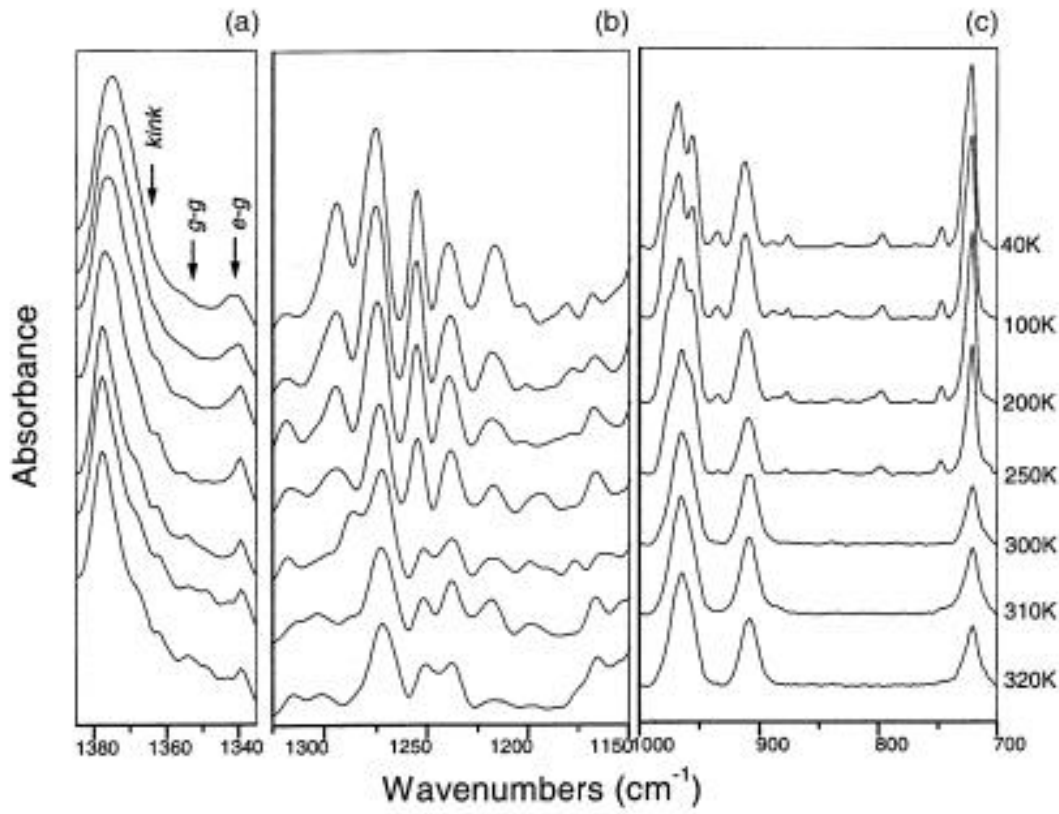

Figure 12. FT-IR spectra at different temperatures of the bilayer phase of the intercalate $\mathrm{Cd}_{0.83} \mathrm{PS}_{3}(\mathrm{CTA})_{0-34}$. (a) The localized methylene wagging modes (1400$\left.1300 \mathrm{~cm}^{-1}\right)$. The wagging modes of specific conformational sequences containing gauche configuration are marked. (b) The methylene wagging progression $\left(v_{8}\right)$ $\left(1350-1150 \mathrm{~cm}^{-1}\right)$ and $(\mathbf{c})$ the methylene twisting-rocking progression $\left(v_{3}\right)(1000-$ $\left.700 \mathrm{~cm}^{-1}\right)$. 


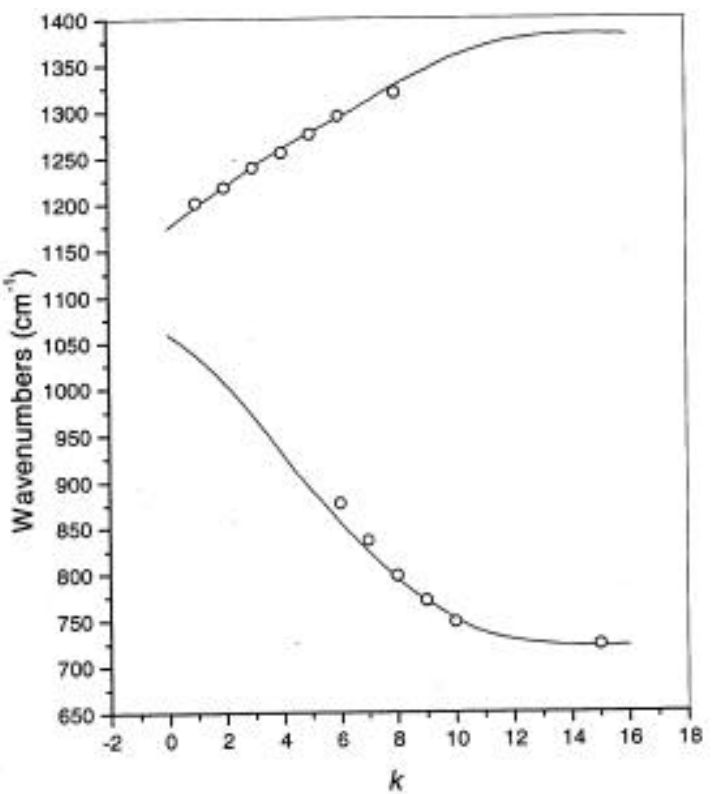

Figure 13. Dispersion curves for the methylene wagging $\left(v_{3}\right)$ and methylene rocking-twisting $\left(v_{8}\right)$ branches of the progression bands for the bilayer compound $\mathrm{Cd}_{0.83} \mathrm{PS}_{3}(\mathrm{CTA})_{0-34}$. The filled circles are the experimental values and the solid line is the calculated dispersion curve for infinite polymethylene chain.

We have analysed the progression series arising from the methylene wagging $\left(v_{3}\right)$ and rocking-twisting modes $\left(\mathbf{V}_{8}\right)$ since these are known to show large dispersion. The $\mathbf{V}_{3}$ and $v_{8}$ progression bands for the intercalated bilayer phase of $\mathrm{Cd}_{0-83} \mathrm{PS}_{3}(\mathrm{CTA})_{0.34}$ are shown in the second and third panel of figure 12. At room temperature, the progression bands especially the $v_{8}$ series are difficult to observe. It is only at low temperature $(40 \mathrm{~K})$ that the progression bands are clearly defined and the $k$ values associated with the $v_{3}$ and $v_{8}$ series assignable ${ }^{11}$. In these assignments all methylene units of the intercalated CTA ion are in trans conformation, i.e. $n=15$ in (1). These have been plotted in figure 13 along with the theoretical dispersion curves for an infinite methylene chain.

The localized wagging modes of the intercalated bilayer phase is shown in the first panel of figure 12, for the corresponding temperatures. At room temperature and above, features due to the double gauche $\left(1354 \mathrm{~cm}^{-1}\right)$ and $g-t-g^{\prime}+$ kink $\left(1368 \mathrm{~cm}^{-1}\right)$ defects (marked by arrows in figure 12a) are clearly defined whereas the progression bands are not. As the temperature is lowered the population of the double gauche and 'kink' $g-t-g$ ' defect conformers decrease, which is as expected since the gauche configuration is higher in energy as compared to the trans. As these gauche conformers disappear, the number of intercalated alkyl chains having a 'all-trans' planar conformation increases. This is reflected in the increase in the intensity of the progression bands due to such planar conformers at low temperature. It may be seen that at $40 \mathrm{~K}$ when the progression bands are easily identified, the defect bands, except for the end gauche, are almost absent. 


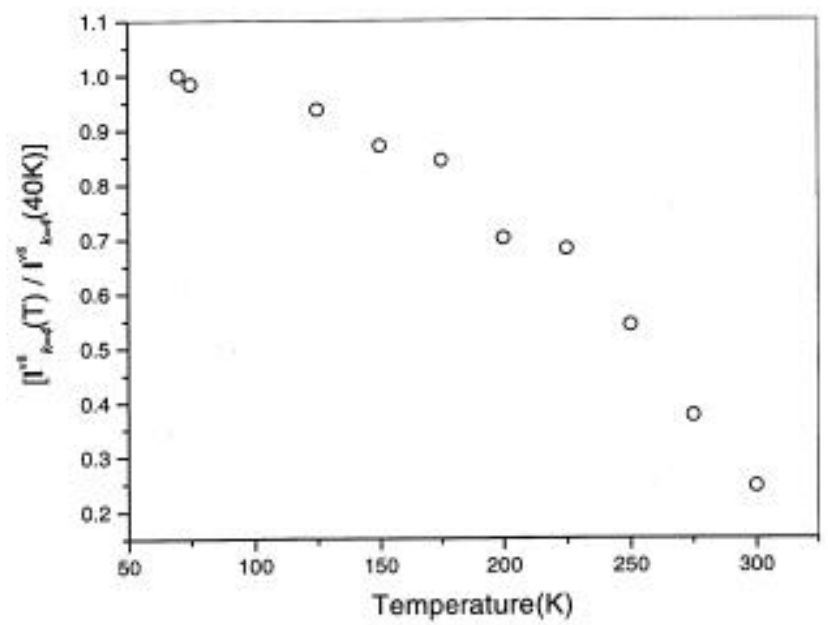

Figure 14. Temperature variation of the fraction of intercalated hydrocarbon chain in an all-trans conformation. The plot shows the temperature dependence of the normalized intensity of the $k=4$ component of the methylene wagging $\left(v_{8}\right)$ progression series.

$300 \mathrm{~K}$

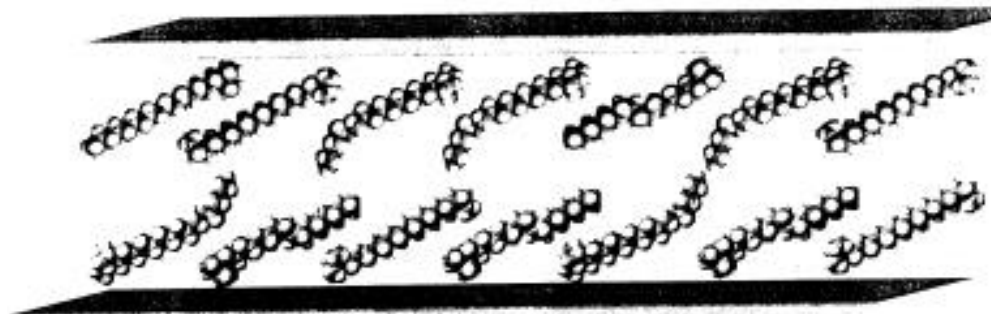

$40 \mathrm{~K}$

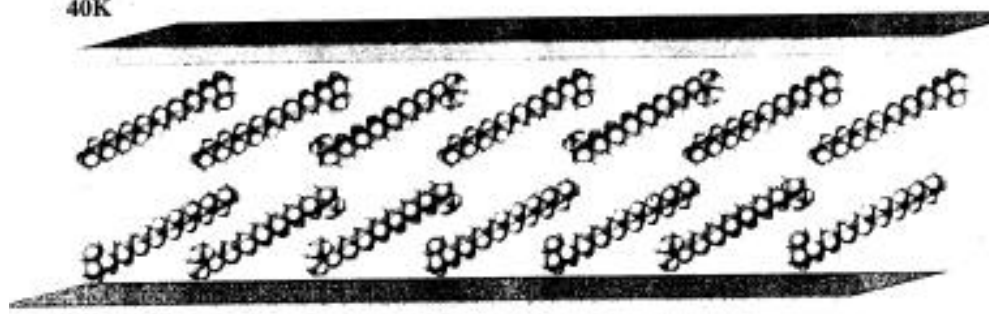

Figure 15. Cartoon representing the conformation of the intercalated surfactant molecules at 300 and $40 \mathrm{~K}$. The population of the high-energy conformers has been exaggerated.

The progression band intensities provide a quantitative measure of methylene chain conformation $^{34}$. Since the progression series is characteristic of a set of $n=15$ coupled oscillators, it is evident that only methylene chains with an all-trans conformation contribute to the progression band intensities. Implicit in this argument is the 
assumption that a single gauche configuration is sufficient to destroy the coupling that produces the progression. Assuming that at the lowest temperature recorded $(40 \mathrm{~K})$ all the methylene units are in an ordered all-trans conformation, then the ratio of the intensities of the progression bands at any temperature with respect to the intensity $\left(I_{0}\right)$ at the reference temperature $(40 \mathrm{~K})$ would be directly proportional to the fraction of the methylene chains of the intercalated surfactant bilayer which have an all-trans conformation. In figure 14 the normalized intensity, $I / I_{0}$, of the $k=4$ component of the $v_{3}$ progression series has been plotted as a function of temperature $\left(I_{0}\right.$ is the intensity at $40 \mathrm{~K}$ ) (the other components of the $v_{3}$ series as well as that of the $v_{8}$ series show a similar temperature dependence). The loss of progression intensity with temperature is a consequence of the increased number of gauche bonds with temperature. Figure 14 therefore represents the temperature variation of the fraction of all-trans methylene chains in the intercalated surfactant bilayer. A schematic depiction of the conformational changes of the intercalated surfactant molecule with temperature is shown in figure 15.

\section{Conclusions}

Cetyl trimethyl ammonium ions have been intercalated within the galleries of layered $\mathrm{CdPS}_{3}$. Depending on the ion-exchange procedure adopted either $\mathrm{Cd}_{0-93} \mathrm{PS}_{3}(\mathrm{CTA})_{0-14}$ or $\mathrm{Cd}_{0-83} \mathrm{PS}_{3}(\mathrm{CTA})_{0-34}$ is obtained. In the former the surfactant ion form a monolayer with the methylene tail of the CTA ion lying flat with the molecular axis parallel to the walls of the gallery. In $\mathrm{Cd}_{0-83} \mathrm{PS}_{3}(\mathrm{CTA})_{0-34}$, however, the surfactant ions adopt a tilted bilayer structure. The tilt angle, the angle between the methylene chain molecular axis and the inorganic layer, is $33^{\circ}$. The present study highlights the importance of the grafting density in determining the organization of the confined surfactant molecules. NMR spectroscopic study clearly indicates the absence of lateral diffusivity of the surfactant ions in both monolayer and bilayer intercalated compounds. Only conformational degree of freedom are available to the confined surfactant ion. The conformation of the hydrocarbon chain of the intercalated surfactant and its temperature dependence have been established using infrared vibrational spectroscopy.

\section{References}

1. Wolfe T A, Demirel T and Baumann E R 1985 Clays and clay minerals 33301

2. Van Y, Bein T 1993 Chem. Mater. 5905

3. Okahata Y and Shimizu A 1989 Langmuir 5954

4. Lagaly G 1976 Angew. Chem., Int. Ed. Engl. 15575

5. Ogawa M and Kuroda K 1997 Bull. Chem. Soc. Jpn. 702593

6. Pavan P C, Gomes G A and Valim J B 1998 Microporous and mesoporous materials 21659

7. Matsuo Y, Hatase K and Sugie Y 1999 Chem. Commun. 43.

8. Price S J, Hare D O, Francis R J, Fogg A and Brien S O Chem. Commun. 2453

9. Venkataraman N V and Vasudevan, S 2000 J. Phys. Chem. B104 11179

10. Venkataraman N V and Vasudevan S 2001 J. Phys. Chem. B105 1805

11. Venkataraman N V and Vasudevan S 2001 J. Phys. Chem. B105 7639

12. Jordan J W 1950 J. Phys. Colloid. Chem. 54294

13. Mortland M M, Shaobai S and Boyd S A 1986 Clays and Clay Minerals 34581

14. Stul M S, Maes A and Uytterhoeven J B 1978 Clays and Clay Minerals 26309

15. Ogawa M, Aono T, Kuroda K and Kato C 1993 Langmuir 26309

16. Vaia R A and Giannelis E P 1997 Macromolecules 308000

17. Ouvrard G, Brec R and Rouxel J 1985 Mater. Res. Bull. 201181 
18. Jeevanandam P and Vasudevan S 1997 Solid State Ionics 10445

19. Israelachvili J N Intermolecular and surface forces: With applications to colloidal and biological systems (London: Academic Press) 1985

20. Arun N, Vasudevan S and Ramanathan K V 2000 J. Am. Chem. Soc. 1226028

21. Length estimated from Insight II molecular modelling system; Biosym Technologies: San Diego, CA, 1993

22. Klingen V W, Ott R, Hahn H 1973 Z. Anorg. Allg. Chem. 396271

23. Wang Li-Qiong, Liu J, Exarhos G J, Flanigan K Y and Bordia R 2000 J. Phys. Chem. B104 2810

24. Cheney B V and Grant D M 1967 J. Am. Chem. Soc. 895319

25. Williams E, Sears B, Allerhand A and Cordes E H 1973 J. Am. Chem. Soc. 954871

26. Ulman A 1991 An introduction to ultrathin organic films: From Langmuir-Blodgett to selfassembly (San Diego: Academic Press)

27. Wallach D F H, Verma S R and Fookson 1979 J. Biochim. Biophys. Acta. 559153

28. Snyder R G, Strauss H L and Elliger C A 1982 J. Phys. Chem. 865145

29. MacPhail R A, Strauss H L, Snyder R G and Elliger C A 1984 J. Phys. Chem. 88334

30. Snyder R G 1967 J. Chem. Phys. 471316

31. Naidu S V and Smith F A 1994 J. Phys.: Condens. Matter. 63865

32. Snyder R G 1960 J. Mol. Spectrosc. 4411

33. Snyder R G and Schachtschnelder J H 1963 Spectrochim. Acta. 1985

34. Tasumi M, Shimaanouchi T, Watanabe A and Goto R 1964 Spectrochim. Acta. 20629

35. Chia N C, Vilcheze C, Bittman R and Mendelsohn R 1993 J. Am. Chem. Soc. 11512050 